\title{
ESTRUTURA DE UM FRAGMENTO DA MATA CILIAR DO RIO CARÁ-CARÁ, PONTA GROSSA, PR
}

\author{
STRUCTURE OF A RIPARIAN FOREST PATCH OF THE \\ CARÁ-CARÁ RIVER, PONTA GROSSA, PARANA STATE, \\ SOUTHERN BRAZIL
}

\author{
ROSEMERI SEGECIN MORO \\ JAIR SCHMITT2 \\ LUIZ AUGUSTO DIEDRICHS ${ }^{3}$
}

1 Professora do Departamento de Biologia Geral da UEPG. Membro do Centro Tecnológico Icomarã

2 Biólogo. Membro do Centro Tecnológico Icomarã

3 Diretor do Departamento de Meio Ambiente da Prefeitura Municipal de Ponta Grossa. Membro do Centro Tecnológico Icomarã

RESUMO

Realizou-se um estudo fitossociológico de um fragmento de mata ciliar, degradada pela ação antrópica, com vistas à recomposição da mesma, no Município de Ponta Grossa, PR, numa região de Floresta Ombrófila Mista Aluvial. A análise demonstrou que a vegetação remanescente mantém a biodiversidade em nível aceitável (índice de diversidade de Shannon Wiener: H’=2,97) para suprir suas próprias necessidades de regeneração sem, no entanto, prescindir de um plano de manejo adequado. Embora tenham sido caracterizadas seis diferentes zonas 
fitofisionômicas (mata secundária tardia, mata de inundação, mata sobre diques marginais, várzea, capoeirão e capoeirinha), apenas as duas primeiras reúnem condições para funcionar como banco de sementes. Como cerca de 75\% das espécies arbóreas determinadas têm dispersão zoocórica, a conservação de outro fragmento adjacente, maior, de mata ciliar primária, é fundamental para permitir a manutenção de um corredor ecológico.

Palavras-chave: mata ciliar; recuperação de áreas degradadas; Floresta Ombrófila Mista Aluvial

\section{Considerações gerais}

Ações de recomposição vegetal em trechos degradados visam atingir dois objetivos distintos, mas não excludentes: procurar "recriar" a vegetação existente no passado, mantendo a composição original em espécies; procurar recuperar o papel da vegetação na regulação do regime hídrico, no fluxo de nutrientes, na estabilidade do solo e na retenção de partículas e insumos agrícolas, ou seja, na retomada da função da mata ciliar.

Um aspecto fundamental na recuperação de matas ciliares está relacionado com a biodiversidade destas formações. A fragmentação destas florestas transforma grandes extensões de habitats em numerosas porções menores isoladas umas das outras, provocando interrupções de importantes corredores ecológicos e, invariavelmente, reduzindo a biodiversidade pelas modificações causadas no processo de fragmentação. Uma característica importante da floresta natural, e que deve, na medida do possível, ser reproduzida na floresta implantada, é o fato das espécies apresentarem poucos indivíduos por unidade de área, o que resulta na alta diversidade de espécies arbóreas nestas formações.

Assim, a proposta de reflorestamento ciliar em trechos degradados deve partir de conhecimentos básicos, dentre os quais destacam-se a utilização de vegetação heterogênea, com espécies de ocorrência regional, cuja seleção tenha considerado aquelas mais adaptáveis às condições de umidade do solo em função de fatores como a maior ou menor distância das margens do rio ou a proximidade de áreas úmidas, sombreadas, planas ou de encosta. Finalmente, a escolha das espécies deve levar em consideração o processo de sucessão secundária verificado em formações naturais, de acordo com o grupo ecológico a que pertencem (RODRIGUES e LEITÃO FILHO, 2000).

PUBLICATIO UEPG - Biological and Health Sciences, 7 (1): 19-38, 2001. 


\section{Objetivos}

Este trabalho visou fornecer subsídios a um programa de recomposição de mata ciliar desenvolvido pelas Cervejarias Kaiser do Brasil Ltda, em sua unidade de Ponta Grossa, PR. Dentro dos princípios norteadores da proposta, a pesquisa teve como objetivos: a) caracterizar fitofisionomicamente o fragmento de mata de acordo com relevo, solo e vegetação; b) selecionar as zonas mais representativas para uma análise fitossociológica; c) descrever a estrutura atual da vegetação ciliar; d) elaborar uma lista de espécies indicadas para a recomposição, de acordo com seu estádio sucessional.

\section{Caracterização da área}

A área em estudo (figura 1) está localizada no município de Ponta Grossa, PR, abrangendo parte da região sudeste do perímetro urbano da cidade (2509'50”S; 5007'10”W), com altitude próxima a 780 metros do nível do mar. Esta área faz parte da bacia hidrográfica do rio Cará-Cará, afluente da margem direita do rio Tibagi, apresentando inúmeras nascentes, grande parte delas, junto à região central da cidade de Ponta Grossa.

O clima da região é do tipo $\mathrm{Cfb}$, segundo a classificação climática de Koeppen, com precipitações médias anuais em torno de 1.507,5 mm, evaporação total de 920,2 mm e quantidade de horas de insolação igual a 2.119,1 h. As temperaturas médias do ar $\left({ }^{\circ} \mathrm{C}\right)$ em Ponta Grossa no período 1954/ 1997 situam-se próximas a $17,8^{\circ} \mathrm{C}$. O relevo da bacia hidrográfica do rio Cará-Cará, de certa forma, representa o relevo das demais bacias que compõem o quadro urbano ponta-grossense. É relativamente acidentado nas cabeceiras dos arroios (nascentes), com encostas íngremes e drenagem entalhada em vales profundos. No restante da área, o relevo é mais suave, com colinas amplas, de pequena amplitude e topos convexos a planos, com raras vertentes mais íngremes.

Em termos geológicos, o substrato do Arroio Olarias é representado por folhelhos argilosos a siltosos da Formação Ponta Grossa, e intrusivas básicas. O Cará Cará situa-se quase todo sobre rochas sedimentares da Formação Furnas. Depósitos mais recentes são representados por aluviões nas 
planícies de inundação, e depósitos sugestivos de importante fase pré-atual de denudação de encostas e entalhamento dos talvegues: leque aluvial, rampas colúvio-aluviais, terraços aluviais (MELO e GODOY, 1997).

Os solos encontrados na bacia hidrográfica e área de estudo são classificados em Latossolo Vermelho Escuro, Podzólico, Cambissolo, Complexo de Cambissolos/Solos Litólicos e Gley Húmico Álico.

\section{Metodologia}

Analisou-se previamente fotos aéreas do local, dado o tamanho reduzido do fragmento. Comparou-se imagens dos vôos de 1980 (esc. 1:25.000) e 1995 (esc. 1:8.000), para avaliação da extensão original e atual da vegetação ripária. Após, procedeu-se checagem de campo dos padrões fitofisionômicos identificados na imagem, produzindo um zoneamento preliminar da área a ser amostrada.

O levantamento fitossociológico foi realizado de maneira a contemplar a amostragem da vegetação em todas as situações ambientais existentes na floresta em questão. Em função da heterogeneidade ambiental das formações ciliares, para avaliar a diversidade local escolheu-se o método de quadrantes (BRAUN-BLANQUET, 1979). Foram analisados dois transectos perpendiculares ao sentido do declive, de 50 e 30 metros, respectivamente, abrangendo 16 pontos equidistantes em 5 metros. Foram determinados os quatro elementos lenhosos mais próximos de cada ponto, independente de seu DAP (diâmetro à altura do peito). Isto ocorreu porque desejava-se incluir na avaliação também os elementos de regeneração natural da formação. Abordaram-se os seguintes parâmetros fitossociológicos (GALVÃO, 1989):

Freqüência relativa (Fr): é calculada através da freqüência absoluta da espécie e a soma total das freqüências absolutas; Índice de Similaridade de Jaccard (J): avalia a semelhança entre duas ou mais comunidades. É uma expressão matemática que elimina o caráter subjetivo da análise, valorando a presença-ausência de espécies (compara pares de comunidades); Índice de Diversidade de Shannon-Wiener (H'): tenta expressar a biocenose numa expressão numérica e estabelecer uma interdependência entre a equitabilidade (uniformidade) de um sistema e seu número de espécies (ri- 


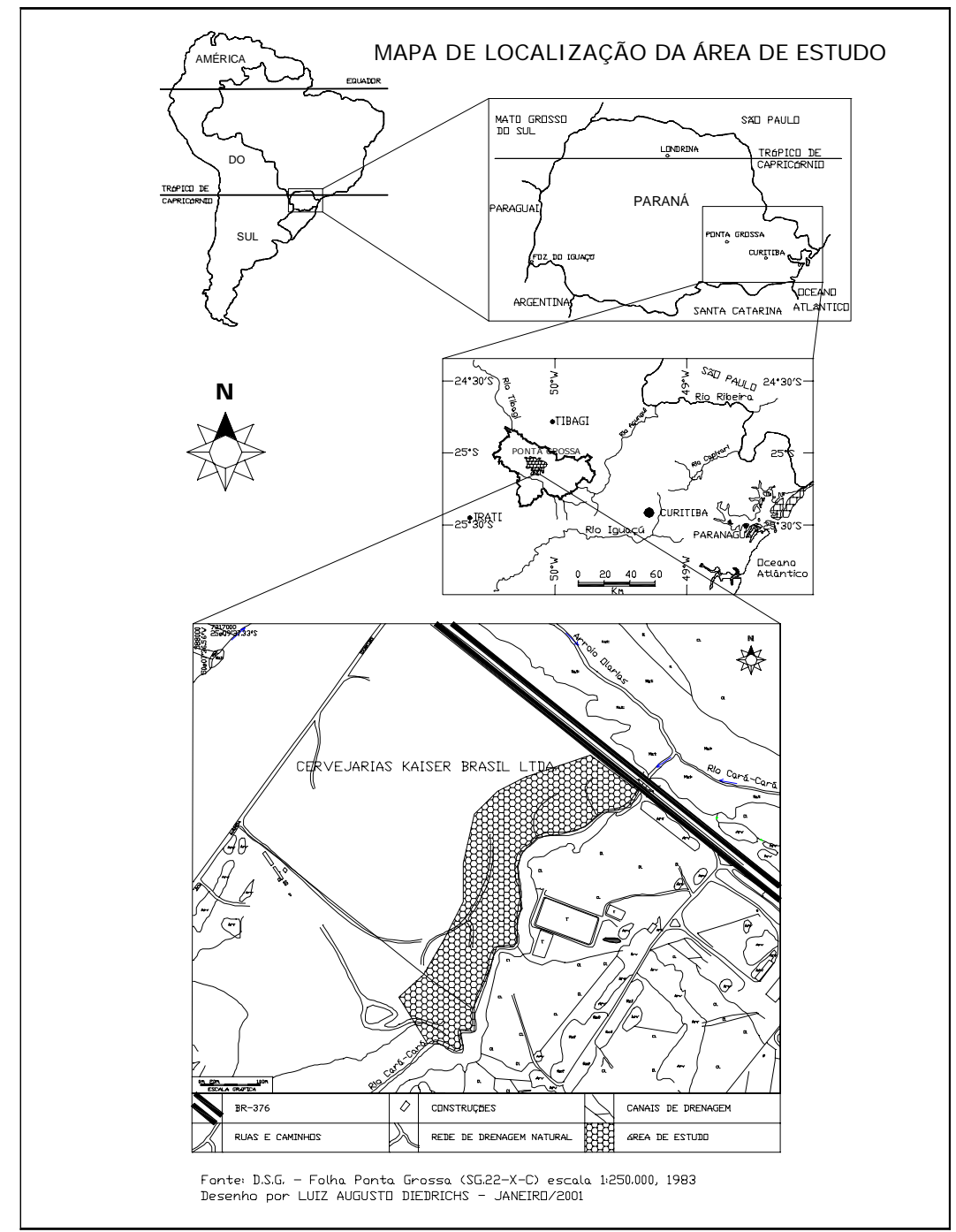

Figura 1 - Localização da área de estudo

PUBLICATIO UEPG - Biological and Health Sciences, 7 (1): 19-38, 2001. 
queza).

Amostraram-se ainda, aleatoriamente, outras formas de vida além de arbustos e árvores, com a finalidade de avaliar, qualitativamente, a riqueza total de espécies.

O material coletado foi determinado e preparado de acordo com as técnicas de Fidalgo e Bononi (1984) no herbário HUEPG. A identificação do material baseou-se em chaves analíticas, comparação com espécimes já existentes no acervo do herbário, e consulta à literatura especializada. Os dados referentes à fenologia e ecologia das espécies foram consultados em Rodrigues e Leitão Filho (2000).

\section{Resultados}

Os levantamentos efetuados têm por objetivo subsidiar as medidas de recuperação das áreas degradadas sendo que as recomendações básicas para revegetação de partes desta área estão fundamentadas na exigência constante na Lei Federal 4.771, de 21/09/65 e alterações posteriores, a qual prevê uma faixa mínima de 30 (trinta) metros de preservação permanente ao longo de cursos d'água de até 10 (dez) metros de largura.

\section{1. Perfil Fitofisionômico}

A floresta ciliar da margem direita do Rio Cará Cará, no trecho compreendido entre 100 e 500m a jusante da ponte da BR 376, ocupa uma faixa de cerca de 50 metros de largura média. A fitofisionomia apresentada pela vegetação pertence à região fitoecológica da Floresta Ombrófila Mista aluvial (VELOSO et al., 1991).

Na figura 2, observam-se as seguintes zonas fitofisionômicas:

- Várzea - espécies herbáceas, com predomínio da taboa (Typha dominguensis);

- Mata de inundação - predominam chal-chal (Alophyllus edulis) e a canela-fedida (Nectandra grandiflora); lianas abundantes, dificultando a visualização do dossel; sub-bosque relativamente escasso;

- Mata sobre diques marginais (não mapeado na fig. 2, devido à escala) - grande número de espécies pioneiras como branquinho (Sebastiania klotzschiana) e bugreiro (Lithraea molleoides); dossel denso, homogêneo; sub-bosque deveria ser denso, mas está antropizado; 
- Mata secundária tardia - maior diversidade arbórea; dossel heterogêneo; presença de epífitas (Tillandsia, Aechmea, Polypodium e Rhipsalis); estrato herbáceo pobre e arbustivo ausente; grande número de plântulas (regeneração abundante);

- Capoeirinha - dominância de vassouras e espécies ruderais herbáceas;

- Capoeirão - associação quase pura de arvoretas de Myrtaceae;

Existem ainda clareiras de inundação com numerosas árvores adultas mortas, evidenciando o impacto sobre área nativa, com ausência atual de vegetação, e grande quantidade de entulho proveniente de inundações.

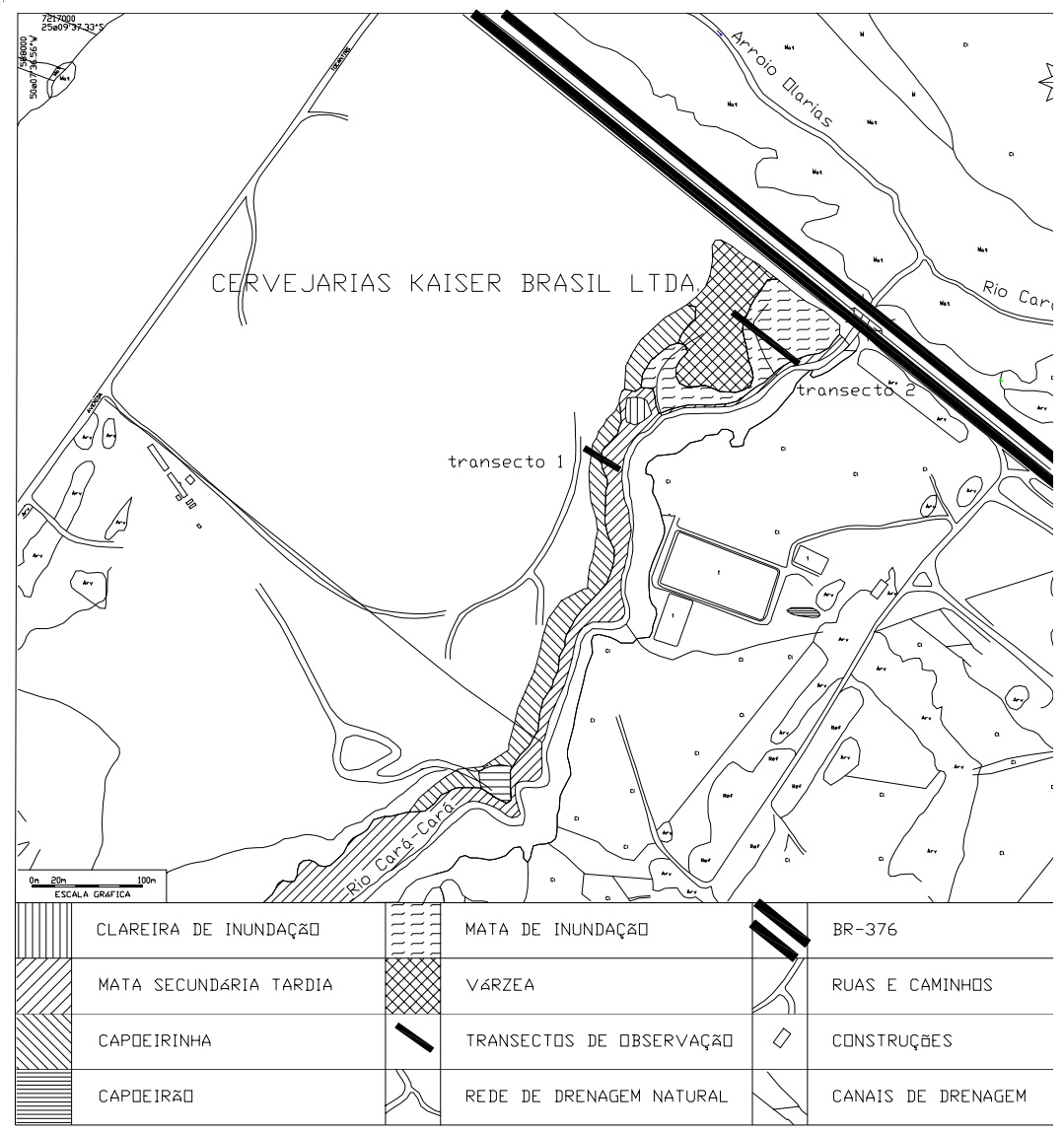

Figura 2 - Zonas fitofisionômicas da área de estudo

PUBLICATIO UEPG - Biological and Health Sciences, 7 (1): 19-38, 2001. 


\section{2. Perfil Fitossociológico}

Os transectos utilizados para o levantamento fitossociológico revelaram dois padrões básicos de distribuição de espécies arbóreas, relacionados ao solo, relevo e hidrologia: mata secundária tardia e mata de inundação. O índice de similaridade de Jaccard entre as duas amostras foi de apenas $28 \%$, evidenciando tratar-se de dois ambientes totalmente distintos dentro da mata ciliar.

O transecto 1 cortou a área desde a margem do rio até o campo, no entorno da mata ciliar (figura 2). Nele, foram analisados 20 táxons arbustivoarbóreos (dois indeterminados), distribuídos em quatro áreas: $\mathrm{A}=$ áreas alagáveis; $\mathrm{B}=$ dique marginal; $\mathrm{C}=$ encosta; $\mathrm{D}=$ campo (figura 3 ). As espécies com maior freqüência relativa (Quadro 1) foram Zanthoxyllum rhoifolium (11,4\%), Sebastiania klotzschiana (11,4\%) e Schinus terebinthifolius (8,6\%).

O transecto 2 cortou a área desde a margem do rio até a várzea limítrofe (figura 2). Foram analisados 12 táxons arbustivo-arbóreos, distribuídos em três áreas: $\mathrm{A}=$ áreas alagáveis; $\mathrm{B}=$ dique marginal; E= várzea (figura 4). As espécies com maior freqüência relativa (Quadro 1) foram Nectandra grandiflora (19,0\%), Lithraea molleoides (14,3\%) e Zanthoxyllum rhoifolium (14,3\%).

O índice de diversidade de Shannon Wiener dos dois transectos foi de 2,78 e 2,28, respectivamente, sendo o índice de diversidade total, $\mathrm{H}^{\prime}=$ 2,97. Para Mantovani (1996), a diversidade das florestas ciliares varia entre 2,85 e 3,84, portanto a diversidade H’ do fragmento do Cará Cará encontra-se dentro do esperado para este tipo de ambiente. Analisando-se isoladamente apenas a diversidade do transecto 2, o valor comparativamente mais baixo da diversidade também encontra respaldo na literatura, que aponta valores de H' entre 1,08 e 3,01 para matas de inundação (MANTOVANI, 1996). 
Quadro 1 - Lista dos táxons determinados nos dois transectos (excluídas uma arvoreta desconhecida no transecto 1 e uma liana lenhosa no transecto 2)

\begin{tabular}{|c|c|c|c|}
\hline ESPÉCIES & TRANSECTO 1 & TRANSECTO 2 & DISTRIBI \\
\hline Alophyllus edulis (chal-chal) & & $\mathrm{X}$ & II \\
\hline Baccharis sp (vassoura) & $\mathrm{X}$ & & \\
\hline Malvaceae & $\mathrm{X}$ & & \\
\hline Lauraceae (canela) & & $\mathrm{X}$ & $\mathrm{V}$ \\
\hline Ilex sp (caúna) & $\mathrm{X}$ & $\mathrm{X}$ & \\
\hline Croton celtidifolius (capixingui) & $\mathrm{X}$ & & II \\
\hline Sapindaceae 1 & $\mathrm{X}$ & $\mathrm{X}$ & \\
\hline Daphnopsis racemosa (embira) & $\mathrm{X}$ & $\mathrm{X}$ & II \\
\hline Gochnatia polymorpha (cambará) & $\mathrm{X}$ & & II] \\
\hline Ilex brasiliensis (congonha) & $\mathrm{X}$ & & \\
\hline Lithraea molleoides (bugreiro) & $\mathrm{X}$ & $\mathrm{X}$ & I \\
\hline Sapindaceae 2 & $\mathrm{X}$ & $\mathrm{X}$ & II \\
\hline Myrtaceae 1 & $\mathrm{X}$ & & \\
\hline Calyptranthes concinna (guamirim) & $\mathrm{X}$ & & II \\
\hline Gomidesia sp & $\mathrm{X}$ & & \\
\hline Myrciaria tenella (cambuizinho) & & $\mathrm{X}$ & II \\
\hline Myrcia multiflora (cambuí) & $\mathrm{X}$ & & II \\
\hline Nectandra grandiflora (canela-fedida) & & $\mathrm{X}$ & I \\
\hline Ocotea puberula (canela-guaicá) & $\mathrm{X}$ & & II] \\
\hline Schinus terebenthifolius (aroeira) & $\mathrm{X}$ & $\mathrm{X}$ & II \\
\hline Sebastiania klotzschiana (branquinho) & $\mathrm{X}$ & & I \\
\hline Syagrus romanzoffianum (jerivá) & & $\mathrm{X}$ & II \\
\hline Zanthoxyllum rhoifolium (mamica-de-porca) & $\mathrm{X}$ & $\mathrm{X}$ & I \\
\hline Desconhecida l & $\mathrm{X}$ & & \\
\hline Desconhecida 2 & $\mathrm{X}$ & & \\
\hline
\end{tabular}

*Padrões de distribuição espacial

I - Alta densidade, distribuição ampla - reúne espécies comuns a outras formações ripárias. II - Densidade variável, distribuição ampla - compreende espécies com distribuição irregular, com muitos indivíduos em alguns locais e poucos em outros, devido a fatores ambientais e antrópicos.

III - Baixa densidade, distribuição ampla - apenas um ou poucos indivíduos, ligados a alguma especificidade do ambiente. $\mathrm{O}$ aumento de sua densidade pode estar relacionado a alterações antrópicas.

IV - Alta densidade, distribuição restrita - população numerosa, ligadas a alguma especificidade restritiva do ambiente.

V - Baixa densidade, distribuição restrita - definidas comumente como raras. 


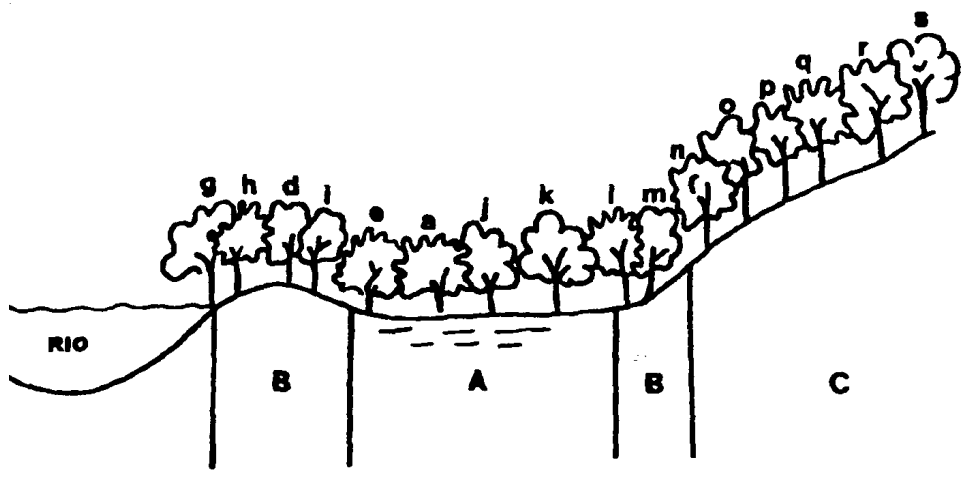

Figura 3 - Perfil esquemático da distribuição de espécies arbóreas na margem direita do rio Cará-Cará, no trecho compreendido entre o rio e a Cervejarias Kaiser do Brasil Ltda. (transecto 1). A: áreas alagáveis; B:

dique marginal; C: encosta.

g) Sebastiania klotzschiana

h) Sapindaceae 1

d) Myrtaceae 1

i) Lithraea molleoides

e) Sapindaceae 2

a) Schinus terebinthifolius

j) Ilex theezans

k) Myrcia multiflora l) Daphnopsis racemosa

m) Gochnatia polymorpha

n) Calyptranthes concinna

o) Zanthoxyllum rhoifolium

p) Gomidesia sp

q) Croton celtidifolius

r) Ocotea puberula

s) Baccharis

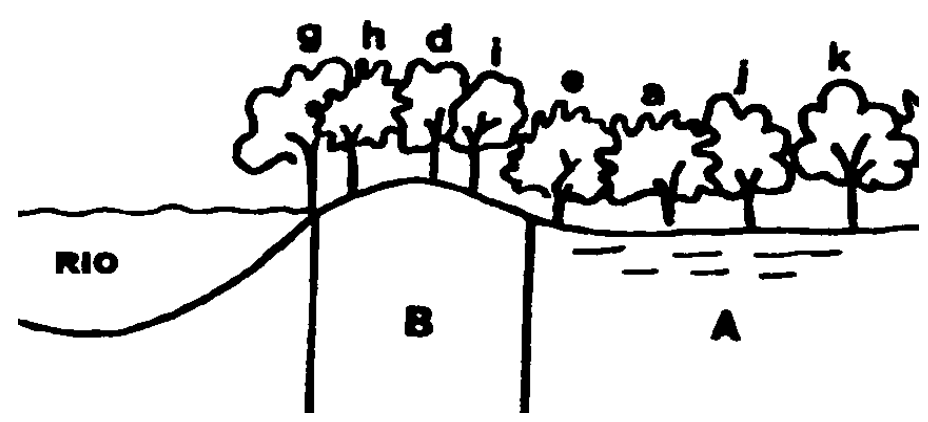

Figura 4 - Perfil esquemático da distribuição de espécies arbóreas na margem direita do rio Cará-Cará, no trecho compreendido entre o rio e a Cervejarias Kaiser do Brasil Ltda. (transecto 2). A: áreas alagáveis; B: dique marginal. 

g) Lithraea molleoides
h) Zanthoxyllum rhoifolium
d) Sapindaceae 2
i) Alophyllus edulis
j) Ilex $s p$

e) Nectandra grandiflora

a) Lauraceae

k) Daphnopsis racemosa

l) Syagrus romanzoffianum

\section{3. Perfil Florístico}

Foram determinados 77 táxons arbóreos, arbustivos e herbáceos, pertencentes a 39 famílias botânicas (Quadro 2). A família melhor representada foi Compositae, com 8 táxons, seguida por Lauraceae (6), Malvaceae, Myrtaceae e Solanaceae (4 cada). A pesquisa bibliográfica da fenologia das espécies arbóreas mostrou que cerca de $75 \%$ delas possui dispersão zoocórica, evidenciando a grande importância de se preservar a mata ciliar para a manutenção dos corredores de fauna, e destes para a continuidade da própria mata ciliar.

Quadro 2 - Listagem das espécies observadas nos estratos herbáceo, arbustivo, arbóreo e epífita da mata ciliar do rio Cará Cará, em novembro e dezembro de 2000, e em coletas anteriores do Herbário HUEPG.

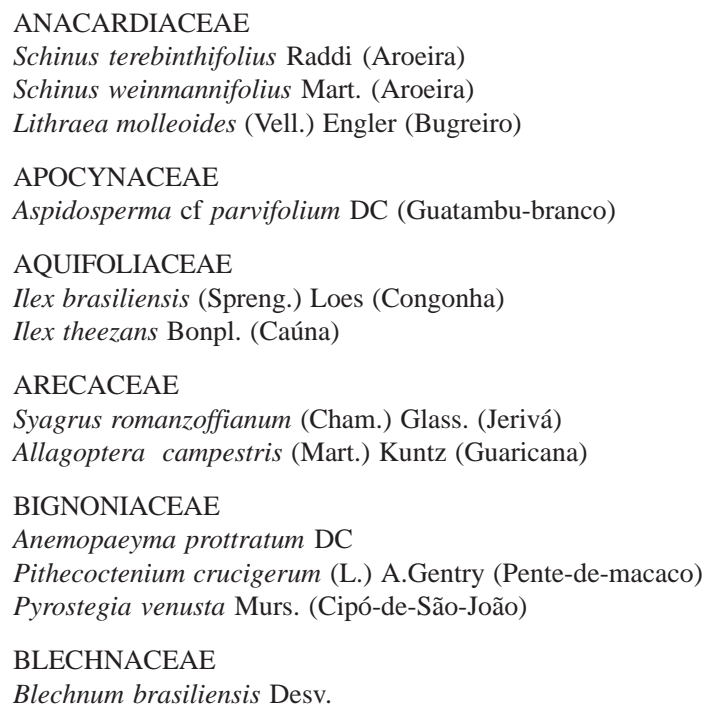




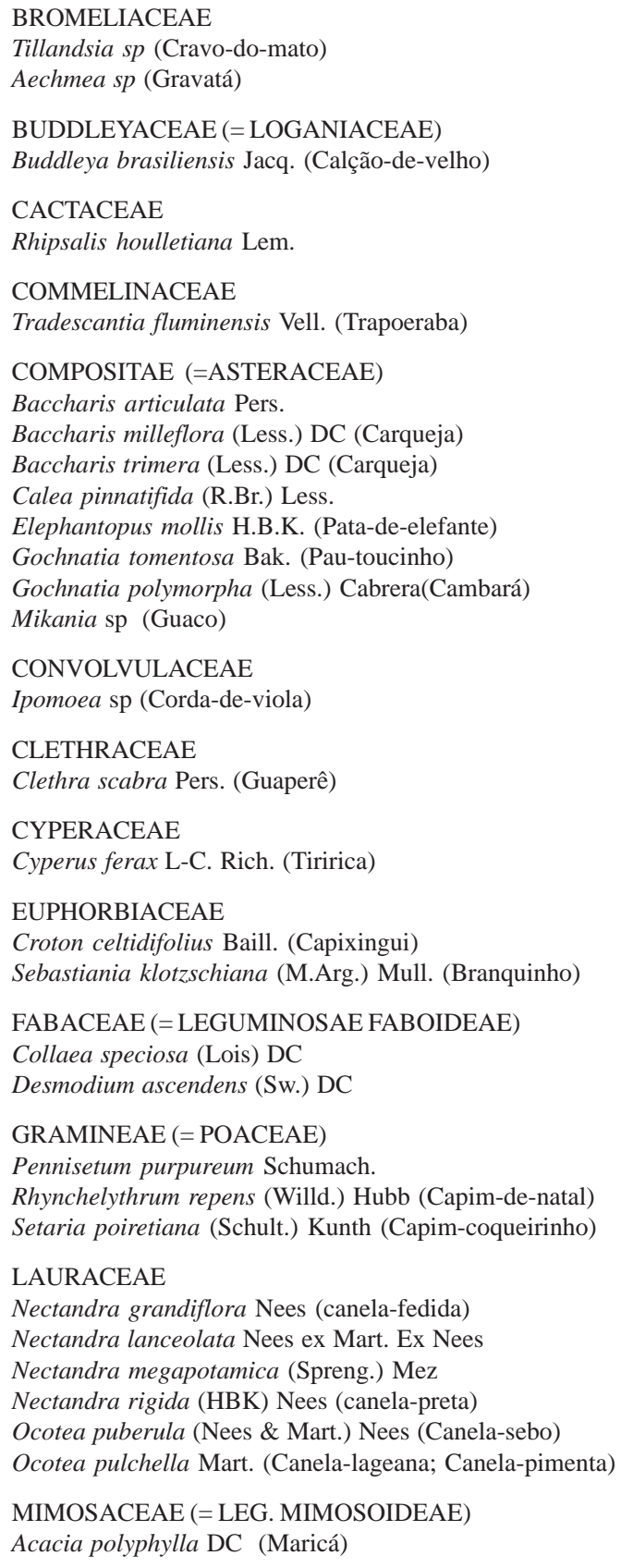




\section{LYTHRACEAE}

Cuphea mesostemon Hoehne (Sete-sangrias)

MALVACEAE

Pavonia communis St. Hill.

Pavonia guerkiana R.E. Fries

Pavonia schrankii Spr.

Peltaea speciosa (Kunth) Standl.

MELASTOMATACEAE

Miconia cinerascens Miq. (Jacatirão)

MYRTACEAE

Gomidesia sp

Calyptranthes concinna DC (Guamirim)

Myrcia multiflora (Lam.) DC (Cambuí)

Myrciaria tenella (DC) Berg (Cambuízinho)

ORCHIDACEAE

Dendrobium sp

PIPERACEAE

Piper gaudichaudianum Kunth (Joelho-de-frango)

POLYPODIACEAE

Polypodium squamulosum Kaulf

Polypodium $s p$

PTERIDACEAE

Pteridium aquilinum (L.) Kuhn (Samambaia-das-taperas)

RHAMNACEAE

Rhamnus polymorpha (Reiss.) Weberb.

ROSACEAE

Rubus sp (Amora-de-sapo)

RUBIACEAE

Psychotria sp

Relbunium wettsteinii Zahlb.

RUTACEAE

Zanthoxyllum rhoifolium (Lam.) Engl. (Juvevê; Mamica-de-porca)

SAPINDACEAE

Alophyllus edulis (St. Hill.) Radlk. (Chal-chal)

Cupania vernalis Camb. (Camboatá; Cuvantã)

Serjania sp (Timbó)

SCHIZACEAE

Anemia phyllitides (L.) Sw.

SELAGINELLACEAE

Selaginella sulcata (Desv.) Spring ex Mart.

SMILACACEAE

Smilax spinosa Mil. (Japecanga) 
32

Anemia phyllitides (L.) Sw.

SELAGINELLACEAE

Selaginella sulcata (Desv.) Spring ex Mart.

SMILACACEAE

Smilax spinosa Mil. (Japecanga)

SOLANACEAE

Cestrum strigilatum R. \& P.

Solanum americanum Hil. (Maria-pretinha)

Solanum gemellum Mart. Ex Sendtn. (Joá-velame)

Solanum nigrum L. (Maria-preta)

THYMELLAEACEAE

Daphnopsis racemosa Griseb (Embira)

ULMACEAE

Trema micrantha (L.) Blum (Crindiúva)

VERBENACEAE

Aegiphila verticilata Vell. (Tamanqueira)

Cytharexyllum myrianthum Cham. (Pombeiro)

Vitex megapotamica (Spr.) Mold. (Tarumã)

\section{4. Estratégias de Recuperação}

\section{4. l. Isolamento da área:}

Embora o isolamento da área seja uma das primeiras providências rotineiramente a serem tomadas, evitando a continuidade do processo de degradação, não nos parece exeqüível na área em questão, em virtude da alta freqüentação por pescadores de caniço. Deve-se tentar disciplinar seu uso, paralelamente a ações de Educação Ambiental.

Itens a serem abordados no controle e retirada dos fatores de degradação:

5. 4. 1. 1. pescadores - elaborar um plano de Educação Ambiental

5. 4. 1. 2. Inundação, vazão subitamente aumentada, contaminação pelo Distrito Industrial, acúmulo de lixo - é um problema da bacia hidrográfica como um todo, e sua resolução deve estar inserida dentro de um plano de gerenciamento da bacia. Como medida paliativa sugere-se a retirada periódica do lixo (originado a montante) acumulado. 
5. 4. 2. Eliminação seletiva ou desbaste de espécies competidoras:

A condição mais comum é a presença de remanescentes de floresta ciliar em condições variadas de degradação, que favorecem a ocupação das bordas e trechos da floresta por espécies agressivas (gramíneas, trepadeiras ou bambus), que competem vigorosamente com a regeneração das espécies dos estratos superiores, dificultando o avanço sucessional.

Bambus e lianas são espécies da própria mata ciliar, favorecidas pela degradação, resultando em populações muito densas e dominantes. Requerem medidas de controle, de maneira a evitar o crescimento excessivo de seus indivíduos e populações.

5. 4. 3. Adensamento de espécies com o uso de mudas ou sementes:

A prática de adensamento consiste no plantio de mudas ou na semeadura direta no interior de uma capoeira ou de um trecho de floresta degradado. Este procedimento visa aumentar as populações de algumas espécies de alta densidade nas formações ciliares que, em função da degradação, tiveram suas populações muito reduzidas na área, podendo estar condicionadas ao isolamento reprodutivo.

5. 4. 4. Enriquecimento de espécies com uso de mudas ou sementes:

Consiste em reintroduzir num remanescente de floresta ciliar degradado, espécies que foram extintas localmente em função da degradação ou do processo sucessional em que se encontra o fragmento a ser recuperado. Tal como no caso anterior, esta reintrodução pode ser feita com o uso de mudas ou de sementes, acelerando a dinâmica sucessional (Quadro 3).

Quadro 3 - Características do ciclo de vida dos componentes arbóreos dos diferentes grupos sucessionais (RODRIGUES e LEITÃO FILHO, 2000, modificado)

\begin{tabular}{|c|c|c|c|c|c|c|}
\hline Legenda & Crescimento & $\begin{array}{c}\text { Altura } \\
\text { (m) }\end{array}$ & $\begin{array}{c}\text { Tolerância } \\
\text { a sombra }\end{array}$ & $\begin{array}{c}\text { Dispersão das } \\
\text { sementes }\end{array}$ & $\begin{array}{l}\text { Idade da } 1^{\text {a. }} \\
\text { reprodução }\end{array}$ & $\begin{array}{r}\text { Tempo } \\
\text { vida }\end{array}$ \\
\hline $\begin{array}{c}\mathrm{P} \\
\text { (Pioneira) }\end{array}$ & Muito rápido & $4-8$ & Heliófita & $\begin{array}{c}\text { Zoocoria (aves, } \\
\text { morcegos) } \\
\text { Anemocoria }\end{array}$ & $\begin{array}{l}\text { Prematura } \\
\text { (1-5 anos) }\end{array}$ & $\begin{array}{l}\text { Muito c } \\
\text { (até } 10 \text { a }\end{array}$ \\
\hline $\begin{array}{c}\mathrm{Si} \\
\text { (Secundária } \\
\text { inicial) }\end{array}$ & Rápido & 20 & Heliófita & $\begin{array}{c}\text { Zoocoria } \\
\text { Anemocoria }\end{array}$ & $\begin{array}{c}\text { Intermediári } \\
\text { a } \\
\text { (5-10 anos) }\end{array}$ & $\begin{array}{r}\text { Curt } \\
(10-25 \text { a }\end{array}$ \\
\hline $\begin{array}{c}\text { St } \\
\begin{array}{c}\text { (Secundária } \\
\text { tardia) }\end{array} \\
\end{array}$ & Médio & $20-30$ & $\begin{array}{c}\text { Heliófita } \\
\text { quando } \\
\text { jovem }\end{array}$ & Anemocoria & $\begin{array}{c}\text { Relativamen } \\
\text { te tardia (10- } \\
\text { 20anos) }\end{array}$ & $\begin{array}{r}\text { Long } \\
(25-11 \\
\text { anos } \\
\end{array}$ \\
\hline $\begin{array}{c}\mathrm{C} \\
\text { (Climácica) }\end{array}$ & $\begin{array}{c}\text { Lento } \\
\text { Muito lento }\end{array}$ & $30-45$ & Ciófita & $\begin{array}{c}\text { Zoocoria } \\
\text { (mamífero) } \\
\text { Autocoria } \\
\end{array}$ & $\begin{array}{c}\text { Tardia } \\
\text { (mais de } 20 \\
\text { anos) }\end{array}$ & $\begin{array}{r}\text { Muito lo } \\
\text { (mais de } \\
\text { anos }\end{array}$ \\
\hline
\end{tabular}


5. 4. 5. Lista de espécies recomendadas de acordo com seus estágios sucessionais e condições de solo

Em primeiro lugar, prioriza-se espécies nativas, pois as espécies que evoluíram no local possuem maior probabilidade de possuírem aí seus polinizadores. A definição destas espécies proveio de um estudo florístico criterioso, complementado por pesquisa bibliográfica de sua fenologia e ecologia.

Nas áreas A e B dos perfis (figuras 3 e 4) ocorrem espécies tolerantes à inundação (foram observadas marcas de até 2 metros de nível de alagamento nos troncos das árvores). Nestas várzeas aluviais e beira de córregos em solos argilosos profundos de drenagem lenta, pode-se indicar:

Allophyllus edulis (St. Hil.) Radlk. - chal-chal, vacum

Blepharocalyx salicifolius (Kunth) O. Berg - cambuí, guamirim

Calyptranthes concinna DC. - guamirim

Cedrela fissilis Vell. - cedro, cedro-rosa

Cryptocarya aschersoniana Mez - canela-amarela

Maytenus ilicifolia Mart. Ex. Reiss. - espinheira-santa

Myrceugenia euosma (O. Berg) D. Legrand - guamirim-da-folhafina, cambuizinho

Nectandra grandiflora Nees - canela-fedida

Nectandra lanceolata Nees ex Mart. Ex Nees - canela-do-brejo

Sapium glandulatum (Vell.) Pax - pau-leiteiro

$\mathrm{Na}$ área C do perfil 1 (figura 3) a drenagem é pouco melhor, embora os solos sejam em sua maioria pobres, úmidos e compactos, com alguma declividade. Espécies que colonizam estes locais são:

Bauhinia forficata Link - pata-de-vaca

Cabralea canjerana (Vell.) Mart. - canjarana, canjerana

Clethra scabra Pers. - guaperê, carne-de-vaca

Cryptocarya lanceolata Nees et Mart. Ex Nees -canela-branca

Erythrina falcata Benth. - corticeira-da-serra, mulungu

Matayba elaeagnoides Radlk. - miguel-pintado

Na área E do perfil 2, com terrenos muito úmidos e brejosos, as espécies de reposição mais indicadas são:

Croton urucurana Baill. Sangra-d'água, urucurana, capixingui

Cytharexyllum myrianthum Cham. - pombeiro 
Erythrina crista-galli L. - corticeira, corticeira-do-banhado Myrciaria tenella (DC.) Berg - cambuí Syagrus romanzoffianum (Cham.) Glassm. - jerivá

Em áreas abertas (clareiras ou orlas da mata ciliar), pode-se optar pelas espécies:

- áreas abertas:

Casearia sylvestris Sw.; Casearia lasiophylla Eichler; Casearia decandra Jacq. - guaçatonga

Croton floribundus Spreng. - capixingui

Luehea divaricata Mart. - açoita-cavalo

Ocotea puberula (Reich.) Nees - canela-guaicá, canela-sebo

Trema micrantha (L.) Blum. - grandiúva

Zanthoxylum riedelianum Engl. - mamica-de-porca, mamica-de-cadela

- nas orlas da mata ciliar, na interface com o campo:

Drimys winteri Forst. - casca-d'anta, cataia

Ilex dumosa Reissek - congonha-miúda, caúna, erva-piriquita

Myrsine ferruginea (Ruiz et Pav.) Mez; Myrsine umbellata (Mart. Ex DC.) Mez - capororoca

Finalmente, algumas espécies são bastante indiferentes às condições de solo:

Alchornea triplinervia (Spreng.) M. Arg. - tapiá-guaçú

Mimosa scabrella Benth. - bracatinga

Nectandra megapotamica (Spreng.) Mez - canela-preta; canela-fedorenta

Nectandra rigida (H.B.K.) Nees - canela-garuva

Prunus sellowii Hoehne - pessegueiro-bravo

Vitex megapotamica Spr. (Mold.)- tarumã

A aroeira não deve ser utilizada como pioneira pois, quando jovem, tem desenvolvimento muito agressivo, com vasto desenvolvimento de ramos laterais junto ao solo, inibindo o desenvolvimento de outras espécies (RODRIGUES e LEITÃO FILHO, 2000). 


\title{
6. Conclusões
}

A resiliência do sistema, isto é, sua capacidade de retornar a um equilíbrio dinâmico após perturbações, foi considerada suficiente e adequada para sua recomposição florística. Chegou-se a esta conclusão levando em conta:

a) presença de cobertura vegetal nativa, com índices de diversidade aceitáveis;

b) presença de banco de sementes de espécies pioneiras;

c) presença de áreas vizinhas florestadas para o aporte de propágulos e formação de corredor ecológico.

Portanto, a recomposição e o manejo do fragmento de mata ciliar estudado revestem-se de importância para preservar e elevar a biodiversidade, proteger os sistemas de drenagem fluvial, controlar os processos erosivos e contribuir para a manutenção de corredores ecológicos.

O programa de recomposição só será plenamente eficiente se acompanhado por um programa paralelo de Educação Ambiental, visto o grande trânsito de pescadores de caniço por toda a área.

Agradecimento

A Cervejarias Kaiser do Brasil Ltda, unidade de Ponta Grossa - PR, pelo apoio financeiro à execução da pesquisa.

Recebido para publicação em 10/03/01.

Aceito para publicação em 12/06/01.

\begin{abstract}
We have carried out a phytosociologic study in a small patch of riparian Araucaria forest at Ponta Grossa, Parana State, Southern Brazil, in order to attend its conservancy. Although one could see six different phytoecological zones (secondary Araucaria forest, floodplain forest, river levées vegetation, wetlands, bushwoods and shrubby meadows, analysis pointed that just the former two areas


could perform seed banks. Shannon Wiener diversity index (H') was 2,97. As 75\% of species have faunal dispersal, we consider fundamental the conservancy of neighbouring forested areas.

Key words: riparian forest; Araucaria Forest; conservancy

Endereço para contato: rsmoro@uepg.br

jschmitt@zipmail.com.br

\section{REFERÊNCIAS}

1 BRAUN-BLANQUET, J. Fitossociologia: bases para el estudio de las comunidades vegetales. Madrid: Blume, 1979.

2 FIDALGO, O.; BONONI, V. L. R. Técnicas de coleta, preservação e herborização de material botânico. São Paulo: Instituto de Botânica, 1984. (Manual, 4)

3 GALVÃO, F. Análise da vegetação arbórea. In: SEMINÁRIO SOBRE AVALIAÇÃO E RELATÓRIO DE IMPACTO AMBIENTAL, 1, 1989. Anais...Curitiba: FUPEF, 1995. p. 108-114.

4 MELO, M. S. de; GODOY, L. C. Geologia, geomorfologia e riscos geológicos na bacia do Arroio Olarias, Ponta Grossa. Publicatio UEPG: Ciências Exatas e da Terra, v. 3, n. 1, p. 33-59, 1997.

5 MANTOVANI, W. Methods for Assessment of Terrestrial Phanerogams Biodiversity. In: BICUDO, C. E. M.; MENEZES, N. A. (Eds.) Biodiversity in Brazil: a first approach. São Paulo: CNPq, 1996. p.119-44. 
38

6 RODRIGUES, R. R.; LEITÃO FILHO, H. de F. (Eds.) Matas ciliares: conservação e recuperação. São Paulo: EDUSP/FAPESP, 2000.

7 STATECOL, S. L. E. Software GW-BASIC versão 2.02. Phoenix Software Associates Ltd., 1984.

8 VELOSO, H. P.; RANGEL FILHO, A. L.; LIMA, J. C. A. Classificação da vegetação brasileira, adaptada a um sistema universal. IBGE: Rio de Janeiro, 1991. 